\title{
Gobernanza y conflicto. Dilemas de la participación social en el proceso de re- urbanización de la Villa 31 y 31 bis en la Ciudad de Buenos Aires (Argentina) ${ }^{1}$
}

\author{
Governance and conflict. The dilemmas of social participation in the re-urbanization \\ process of Villa 31 and 31 bis in the City of Buenos Aires (Argentina)
}

\author{
María Cecilia Zapata ${ }^{2}$ \\ María Florencia Rodríguez ${ }^{3}$ \\ María Soledad Arqueros Mejica ${ }^{4}$ \\ María Carla Rodríguez ${ }^{5}$
}

\section{Resumen}

El objetivo del artículo consiste en analizar los procesos de participación social y conflicto generados en el marco del Programa de Re-urbanización de la Villa 31 y 31 bis impulsado por el Gobierno de la Ciudad de Buenos Aires -GCBA- (Argentina) desde el 2016 hasta inicios de 2019.

A través de una metodología cualitativa de construcción de datos primarios provenientes de entrevistas en profundidad (a habitantes de la villa, integrantes de organizaciones sociales, funcionarios y trabajadores estatales) y observación participante en mesas de diálogo con actores técnicos impulsadas por el organismo ejecutor de la política, se pudo evidenciar que

\footnotetext{
1

${ }^{2}$ Doctora en Ciencias Sociales, Magíster en Administración Pública, Licenciada y Profesora en Sociología por la Universidad de Buenos Aires. Investigadora Adjunta del CONICET y del Instituto de Investigación Gino Germani (Universidad de Buenos Aires). Docente de grado y posgrado en la Universidad de Buenos Aires. Pte. Uriburu $9506^{\circ}$ Piso Oficina 16. E-mail: ceciliazapata@gmail.com. Ciudad de Buenos Aires, Argentina.

${ }^{3}$ Doctora en Ciencias Sociales por la Universidad de Buenos Aires. Magíster en Diseño y Gestión de Programas Sociales de la Facultad Latinoamericana de Ciencias Sociales (FLACSO). Licenciada y Profesora en Sociología por la Universidad de Buenos Aires. Es investigadora asistente del CONICET y del Instituto de Investigaciones Gino Germani (Universidad de Buenos Aires). Docente de grado y posgrado. Pte. Uriburu $9506^{\circ}$ Piso Oficina 16. E-mail: mafloro@gmail.com. Ciudad de Buenos Aires, Argentina.

${ }^{4}$ Doctora en Ciencias Sociales y Licenciada en Sociología por la Universidad de Buenos Aires. Magíster en Economía Urbana de la Universidad Torcuato Di Tella. Becaria posdoctoral CONICET con sede en el Instituto de Investigaciones Gino Germani (Universidad de Buenos Aires). Profesora regular de la Universidad Nacional de Avellaneda y docente de posgrado en la FADU-UBA. Pte. Uriburu $9506^{\circ}$ Piso Oficina 16. E-mail: soledad.arqueros@gmail.com. Ciudad de Buenos Aires, Argentina..

${ }^{5}$ Doctora en Ciencias Sociales de la Universidad de Buenos Aires. Magister en Sociología Económica de la Universidad de San Martín. Es investigadora independiente del CONICET y del Instituto de investigaciones Gino Germani (Universidad de Buenos Aires). Profesora titular regular de teoría urbana en la Carrera de Sociología de la UBA. Docente de posgrado en instituciones nacionales y extranjeras. Pte. Uriburu $9506^{\circ} \mathrm{Piso}$ Oficina 16. E-mail: trebol1968@gmail.com. Ciudad de Buenos Aires, Argentina.
} 
existe gran descontento de los habitantes en torno a las instancias de participación social esgrimidas por el programa, con altos niveles de conflictividad territorial.

Esto da cuenta que los permanentes mecanismos de participación impulsados en la ejecución de política no son garantía per sé de que todos los actores tengan el mismo peso en la toma de decisiones. Más bien las distintas técnicas desplegadas por la nueva gobernanza remiten a prácticas de legitimación de una política habitacional que implícitamente busca la valorización de la ciudad neoliberal, lejos de construir instancias de consenso y participación real que redunden en la reducción de la desigualdad socio-urbana.

Palabras Claves: gobernanza, participación social, conflicto, reurbanización villa, Buenos Aires.

\section{Abstract}

The objective of the article is to analyze the processes of social participation and conflict generated within the framework of the Re-urbanization Program of Villa 31 and 31 bis promoted by the Government of the City of Buenos Aires (GCBA) (Argentina) since 2016 until today.

Through a qualitative methodology of construction of primary data coming from in-depth interviews (to inhabitants of the town, members of social organizations, officials and state workers) and participant observation in dialogues with technical actors driven by the executing agency of the political, it was evident that there is great discontent of the inhabitants around the instances of social participation wielded by the program, with high levels of territorial conflict.

This implies that the permanent mechanisms of participation in the execution of policy are not guarantee per I know that all the actors have the same weight in the decision making. Rather, the different techniques deployed by the new governance refer to practices of legitimation of a housing policy that implicitly seeks the valorization of the neoliberal city, far from building instances of consensus and real participation that result in the reduction of socio-urban inequality.

Keywords: governance, social participation, conflict, urban redevelopment, Buenos Aires.

\section{Introducción}


En el presente artículo se analizan los procesos de participación social que se generaron en el marco del Programa de Re-urbanización de la Villa 31 y 31 bis impulsado por el gobierno de la Ciudad de Buenos Aires (Argentina) desde el año 2016 hasta inicios de 2019 (momento de cierre del trabajo de campo). Esta intervención estatal tiene lugar en el marco de una reestructuración urbana de la zona portuaria-ribereña de la ciudad, con repercusiones hacia la Región Metropolitana de Buenos Aires (RMBA) ${ }^{1}$ a partir de un reforzamiento de la centralidad de la ciudad en el eje norte-sur e impulso de la valorización inmobiliaria mediante venta de activos públicos, inversiones públicas, privadas y financiamiento internacional. En efecto, la villa 31 y 31 bis se localiza en el corazón de un mega-proyecto de renovación urbana que los gobiernos nacional y local fueron impulsando en la zona desde comienzos de la década del ‘90.

El Proyecto de Re-urbanización que la Secretaría de Integración Social y Urbana del Gobierno de la Ciudad de Buenos Aires (SISU-GCBA) implementa en el barrio involucra distintos componentes ${ }^{2}$. Específicamente en materia habitacional se prevé la titulación de terrenos a partir de la ejecución de una política de regularización dominial, el mejoramiento habitacional en el macizo autoproducido e intervenciones de obra nueva en terrenos lindantes al barrio para casos puntuales de realojamiento. Todas estas obras se promueven desde el nivel estatal a partir de la incorporación de una retórica participativa hacia los vecinos del barrio, e incluso, los mismos funcionarios ejecutores de la política argumentan tratarse de un programa originado en el paradigma de una nueva gobernanza urbana producto de las transformaciones que sufrieron las ciudades $-\mathrm{y}$ con ellas el Estado (Brenner y Theodore, 2002; Harvey, 2007)- durante las últimas décadas del siglo XX (Theodore, Peck y Brenner, 2009; De Mattos, 2010; Harvey, 2004 y 2007).

No obstante, la ejecución de la reurbanización se desarrolla con cierto nivel de conflictividad a nivel territorial. A pesar de las numerosas instancias de participación construidas verticalmente por el Estado local para la implementación del proyecto, a partir de diciembre de 2017, comenzaron a visibilizarse expresiones de resistencia, descontentos e incertidumbres por parte de los destinatarios de la política que ponen en cuestionamiento a las instancias de participación social esgrimidas por el programa.

Desde este prisma entonces, surgen algunos interrogantes: ¿Cómo se caracterizó el entramado institucional de participación social promovido por el Proyecto de re- 
urbanización? ¿Qué formatos participativos se impulsaron desde el Programa (Rofman, 2007; Cohen y Arato, 2000; Coraggio, 2003; Cardenalli y Rosenfeld, 2002; García Delgado y De Piero, 2001)? ¿Existieron instancias de real decisión de los destinatarios de las obras de vivienda nueva y rehabilitación? ¿Existió algún tipo de recuperación de la trayectoria participativa pre-existente en el barrio? ¿Qué originan, entonces, los conflictos territoriales en torno a las instancias de participación promovidas por el Estado?

El abordaje metodológico, de tipo cualitativo, combina el análisis de datos secundarios (datos censales e informes de gestión, encuesta propia con inquilinos ${ }^{3}$ y diversas fuentes documentales) con el acopio de datos primarios construidos a través de la realización de entrevistas en profundidad con habitantes seleccionados a partir de una tipología que contempló la condición de tenencia (propietarios, propietarios residentes en el barrio que alquilan piezas e inquilinos), localización intrabarrial (zonas diferencialmente afectadas por las medidas de urbanización y accesibilidad diferencial a la trama urbana consolidada) y género. Este trabajo de campo se inscribe en el marco de un proyecto más amplio donde se entrevistaron a habitantes de distintas villas (Villa 31 y 31 bis, Rodrigo Bueno y Playón de Chacarita) localizadas en áreas centrales de la ciudad actualmente atravesadas por procesos de reurbanización. En este caso, recuperamos el relevamiento realizado en la Villa 31 y 31 bis, en la que pudimos entrevistar a 9 habitantes (hombres y mujeres mayores de edad). También recurrimos a informantes clave -integrantes de organizaciones sociales de base territorial, funcionarios y trabajadores estatales- quienes a través de su injerencia en el barrio aportaron datos relevantes para este trabajo y, nuestra participación -durante el año 2017en mesas de diálogo con actores técnicos impulsadas por el organismo ejecutor de la política (la SISU-GCBA). La sistematización de notas de campo y entrevistas en profundidad nos permitieron abonar a estos interrogantes referidos al proceso de reurbanización y el papel de los habitantes en las instancias de participación promovidas por el GCBA.

\section{Gobernanza urbana y participación social}

El perfil de las políticas públicas -entre ellas, la habitacional- sufrió una transformación significativa orientada específicamente a un proceso en donde el Estado reconfiguró sus capacidades sociales en función del desarrollo del mercado. Las nuevas formas de gestión pública implicaron, por un lado, la transferencia de responsabilidades y 
funciones asociadas de la gestión y ejecución de la política social a distintos niveles gubernamentales (provinciales y municipales) con la participación de la sociedad civil agrupada y de los destinatarios de las políticas (Andreanucci, Neufeld, y Raggio, 2000); y por otro, se conformaron de manera ad-hoc organizaciones de base involucradas activamente en el proceso de implementación y gestión de algunos programas sociales para la realización de acciones inmediatas (como proveerse de alimentos, alcanzar la titularidad de la tenencia de los terrenos, etc.). Brenner (2004) y Jessop (2002) definieron estas estrategias como medidas de reterritorialización en el marco de la reestructuración neoliberal del mercado. Este proceso forma parte de las nuevas estructuras globales del neoliberalismo que afectaron intensamente a los espacios locales, convirtiendo a las mismas ciudades en mercancía y en nodos estratégicos articuladores de los flujos de la economía global (Borja y Castells, 1997; Sassen, 2003, 2007). Dicho re-escalamiento territorial de la política se basa en ceder a la ciudades y a las regiones mayor autonomía política para el desarrollo de políticas locales y el despliegue de formas locales de cohesión (Díaz Orueta, 2013; Rodríguez, 2018). Esto implicó entonces un mayor margen de apertura y pluralismo en la elaboración e implementación de las políticas que incluyeron nuevos formatos de gestión urbana. Los desafíos que impusó la economía globalizada se constituyeron en los principales argumentos para legitimar el re-escalamiento -también- de la gestión urbana. Pues en la actualidad, la complejidad de las problemáticas urbanas exige un abordaje de la mínima unidad político administrativa de gobierno (la local) en articulación con otros actores no gubernamentales con asiento territorial (BM, 2000; OCDE, 2001; CEPAL, 2016; ONU, 2017; AL-LAS, 2017). Estas nuevas formas de gestionar lo público fueron acuñando el término -en lo estrictamente urbano- de "nueva gobernanza urbana", para dar cuenta de la mayor injerencia de actores no gubernamentales en el procesamiento de los asuntos públicos, en la definición y ejecución de políticas públicas y en la prestación de servicios (Aguilar Villanueva, 2006) ${ }^{4}$. Esta noción apunta a focalizar en la complejidad del proceso de toma de decisiones a partir de la participación de diversos actores del sector público, privado y de la sociedad civil que intervienen en los procesos decisorios con intereses divergentes (Jordán, Riffo y Prado, 2017; Zurbriggen, 2011).

Ahora bien, la noción de "nueva gobernanza urbana" dejó de ser un concepto meramente descriptivo de una forma de gestión acuñada a escala regional, para comenzar a imponerse desde los '90 por importantes organismos internaciones, tales como el Banco 
Mundial (BM), el Banco Interamericano para el Desarrollo (BID), la Organización para la Cooperación y el Desarrollo Económico (OCDE) y el Programa de la Naciones Unidades para el Desarrollo (PNUD) como un modelo de gestión a seguir, como el tipo de gobierno "apropiado" para el nuevo milenio. En sintonía con los preceptos de las teorías neoliberales, entre las recomendaciones realizadas por estos organismos a países receptores de sus "ayudas financieras", se resaltan determinadas características que deben asumir los procesos de gobernabilidad: transparencia, eficacia, estabilidad institucional, seguridad jurídica, y de nuestro especial interés- participación social; cualidades que se consideran necesarias para garantizar un funcionamiento eficaz de las fuerzas del mercado. Esto impulsó en el desarrollo de la gestión urbana la promoción de una mayor participación del sector privado y de la sociedad civil en áreas hasta entonces reservadas al sector público (Jordán, Riffo y Prado, 2017; Zurbriggen, 2011).

Pero estos nuevos formatos no siempre se tradujeron en un diálogo fluido entre Estado y sociedad, ni en pautas más vinculantes de participación social que produzcan cambios profundos en la estructura socio-urbana de las ciudades, crecientemente desiguales y segmentadas. Más bien, lo que se pudo ver con la ejecución del Proyecto de Reurbanización de algunas villas de la Ciudad de Buenos Aires, y con fuerza en la 31 y 31 bis, es que en todos los casos dichos procesos estuvieron asociados a la ejecución de grandes proyectos urbanos y/o grandes obras de infraestructura orientadas a la dinamización económica de la ciudad, en la que la nueva gobernanza urbana y la retórica participativa funcionaron como estrategias de legitimación de tal proceso de mercantilización. Estos procesos expusieron el estrecho vínculo entre el estado y el mercado, y también, los límites de las instancias de participación para la canalización de los intereses de la sociedad civil.

A partir de 2015, con la gestión de Horacio Rodríguez Larreta como Jefe de Gobierno porteño, la idea de participación asumió un papel clave para la SISU, por ser uno de los requerimientos fundamentales señalados por el BM y el BID, organismos con injerencia en el financiamiento de la reurbanización de la villa 31 y 31 bis (Capalbo, 2019a). Por lo que esto invita a reflexionar acerca de qué se entiende entonces por participación social en el marco de esta nueva gobernanza urbana.

La participación social remite a un proceso a partir del cual las personas identifican problemas, proponen y negocian alternativas de solución, entendiendo que para cada 
problema existe un abanico de posibles resoluciones y que cada alternativa puede responder de manera precisa - o no- a los intereses de determinados actores sociales (De La Mora, 1992; 2002). Siguiendo este marco conceptual, la participación más genuina y eficaz, resulta ser la conquistada por las organizaciones sociales, aunque -siguiendo al mismo autor- también pueden darse esquemas participativos espontáneos, inducidos e, incluso, impuestos. Más allá del formato que adquiera, la participación social supone entonces una articulación entre actores, cualquiera sea su origen (promovida desde el Estado -inducida o impuesta- o gestionada por éste como resultado de las demandas de la población -conquistada-), y es concebida como parte del proceso mismo de toma de decisiones de la política pública (Catenazzi y Chiara, 2009). Pero los actores que intervienen en esta participación no son actores imparciales, sino que cuentan con valores, intereses, visiones propios que guían su acción y no necesariamente coinciden con los de quienes orientan la política. Incluso, los intereses propios de los funcionarios, la utilización estratégica que estos pueden hacer de la información surgida de los espacios participativos, el accionar de otros actores y el devenir del propio proceso político abren amplias oportunidades para que se desvíe la marcha de un programa hacia otros objetivos, resultados o intereses (Rodríguez y Di Virgilio, 2011).

En esta línea, a partir del caso de análisis de este artículo y retomando los planteos de Cunill Grau (1995) se quiere poner en tensión aquí la modalidad institucionalizada de participación social desde la esfera estatal. La autora plantea que en muchas ocasiones la participación social institucionalizada desde el Estado puede ser explicativa de sus propios límites, habida cuenta que en vez de facilitar el incremento de la representación social, ella puede legitimar la propia corporativización del aparato estatal. Esto llevaría a pensar, por tanto, que el desarrollo de mecanismos de participación social desde el Estado no necesariamente estimula la organización social, sino que puede devenir en desarticulación del tejido social y/o fortalecimiento de las asimetrías en la representación social, redundando en un debilitamiento de la sociedad civil. Para dar cuenta de esto, De la Mora (2002) remite a tres tipos de relación entre el Estado y la sociedad en el marco de formatos desplegados para la participación social: la clientelista, en la que representantes estatales encuentran en esa articulación su legitimación en el poder demostrando eficacia con las organizaciones de base, y construyendo una articulación acrítica; la maniqueista, en la que tanto representantes del Estado como de la sociedad civil no creen obtener alguna contribución a partir de la articulación entre ellos (los primeros por considerarse dueños y sabedores de un 
conocimiento técnico suficiente para intervenir en la realidad y los segundos por considerar a los primeros oportunistas que sólo quieren capitalizar políticamente las energías desplegadas por las organizaciones sociales); y la crítica, que recupera los elementos superadores de los dos modos de vinculación anteriores a partir del reconocimiento mutuo de sus identidades diferentes y logran en el formato participativo una articulación basada en la integración y asimilación de las identidades y autonomías del otro y propias desde un posicionamiento crítico.

Para poder abordar la institucionalización de la relación del Estado (que en las últimas décadas asume las características de neoliberal) con la sociedad por medio de la participación social en el marco de una gestión urbana es necesario tener en consideración a los sujetos de la participación desde sus valores e intereses, las modalidades de participación que se despliegan para ello, así como también los ámbitos en los que se ejerce la participación a lo largo del tiempo ${ }^{5}$.

Existen profusos debates vinculados al sentido y los objetivos de la adopción de formatos participativos en una política. Rofman (2007) plantea que desde enfoques liberales estos espacios pueden devenir en aportes de eficiencia y transparencia de actores no gubernamentales en la gestión, hasta discursos transformadores que visualizan en estas estructuras vías para el estímulo a la participación, a la ampliación de ciudadanía de sectores empobrecidos e incluso como canales de involucramiento en la toma real de decisiones y ejercicio pleno de ciudadanía.

En línea con nuestro tema de análisis, los organismos internacionales promovieron por décadas la participación con las comunidades locales a los fines de dar cuenta de mecanismos de transparencia institucional y también como "dispositivo para generar mayor legitimidad en los proyectos que financian” (Capalbo, 2019b:447). En esta relación Estadosociedad civil, la participación promovida por estos organismos aparece reducida al espacio de diálogo entre actores -con cierta primacía del consenso (más que del conflicto) y en pos de un proceso de transformación individual (más que colectivo)-, en tanto supuso que a partir del diálogo sobre las problemáticas que afectaban a la comunidad los sujetos presentes tomarían conciencia de lo que sucede y contribuirían en la implementación de la política que mejoraría sus condiciones de vida (Capalbo, 2019b). Esta mirada de la participación fue la impulsada por la SISU, quien justificó mediante informes varios la cantidad de reuniones y 
los diálogos institucionalizados desplegados con los habitantes del barrio 31 y 31 bis. La injerencia de estos organismos internacionales se hizo visible también de manera espacial, con la construcción de la sede del Banco Interamericano de Desarrollo en la propia villa.

Tales cuestiones nos invitan a seguir pensando acerca de las formas de participación y los alcances de las mismas en un marco específico de implementación de una política. Retomando a Rofman, el autor argumenta que los resultados de la participación pueden ser diversos, ya que existen experiencias de efectivo empoderamiento de los grupos destinatarios y de ampliación de los mecanismos democráticos, hasta casos en los que los actores sociales intervienen bajo formas tuteladas y controladas, que implican una legitimación de la dominación política (Rofman, 2007). De manera complementaria Pelli (2007) advierte sobre esta cuestión remitiendo al concepto de la falsa participación de los adjudicatarios en los programas destinados a resolver el acceso a la vivienda social, pues argumenta que funcionarios estatales o técnicos de organizaciones sociales (empoderados de un saber técnico, profesional y en una posición de mayor poder en la estructura social) actúan convencidos de estar trabajando en marcos ampliamente participativos porque existen espacios de "información" a los destinatarios de la política, o de opinión en la que los destinatarios pueden verter sus puntos de vista o instancias de "aprobación" de lo que los técnicos y/o profesionales pensaron por ellos. Pero estos espacios "participativos" distan de ser instancias de real toma de decisión de los destinatarios de la política. Pues en el marco de una política social -y específicamente en una política urbana-, la participación social implica un proceso de redistribución de recursos, de poder de gestión y una reducción de distancias que genera una redefinición de la relación entre el Estado y la sociedad y una redistribución de las tomas de decisión (Zapata, 2017). Por lo que la participación en el marco de una política social -entendida como campo de disputa- va a implicar necesariamente, una situación -por lo menos- de tensión en el acto de gestionar, ceder y/o apropiar esos recursos.

\section{Un repaso histórico. La villa 31, disputas y tensiones en un área de renovación}

La villa 31 y 31 bis se localiza en el barrio porteño de Retiro, en la Comuna 1 de la Ciudad de Buenos Aires área céntrica con gran afluencia de flujo vehicular, terminales de diversos medios de transporte público, instalación de comercios, oficinas de áreas 
gubernamentales e importantes empresas, a lo que se suman grandes emprendimientos inmobiliarios (construcción de torres con amenities para sectores gerenciales). Su localización en el extremo norte de la ciudad capitalina de la Argentina, refuerza la centralidad en proximidad a una de las zonas más cotizadas de Buenos Aires: Puerto Madero (barrio orientado a sectores de altos ingresos). El Censo 2017 realizado por la SISU y la Dirección de Estadística y Censos del GCBA arrojó un total de 40.087 personas residentes en la villa distribuidas en 12.783 hogares, de los cuales se estima que casi el $30 \%$ son inquilinos (SISU, 2017a).

Mapa 1: Localización de Villa 31 - 31 bis - Comuna 1, Ciudad de Buenos Aires (Argentina).

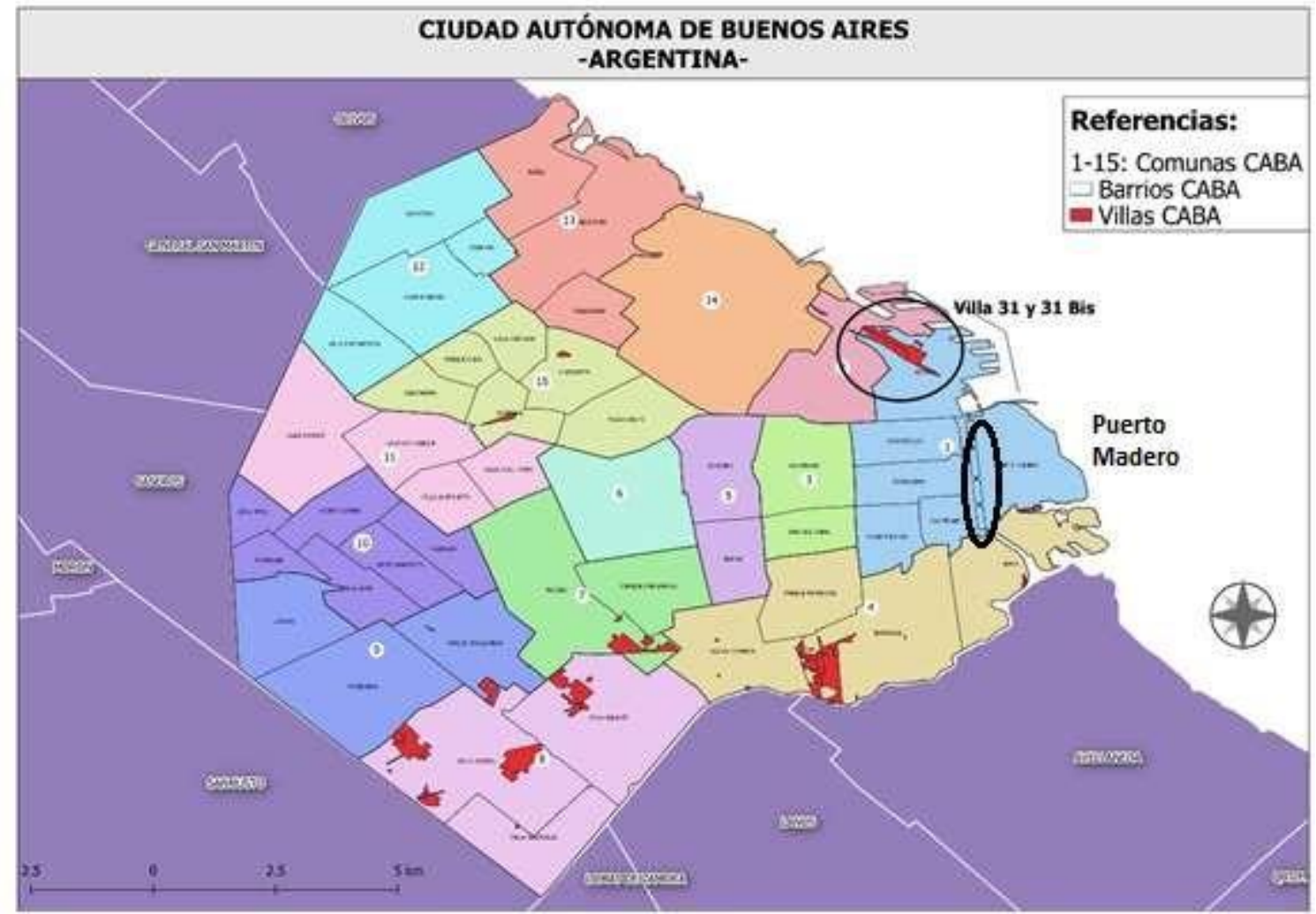

Fuente: Elaboración propia en base a QGIS.

La villa 31 es una de las más antiguas de la Ciudad de Buenos Aires. Los primeros asentamientos poblacionales en el área de inserción de la villa tuvieron lugar en la década de 1930 como consecuencia de una oleada migratoria de trabajadores precarizados del 
campo a la ciudad. Por aquellos años se conformaron Villa Desocupación, Villa Esperanza y Barrio Inmigrantes, que se localizaron en el espacio que hoy ocupa la Villa 31-31 bis (Rodríguez y Vitale, 2016). El barrio creció en las décadas siguientes (Sehtman, 2009) y hacia mediados de la década de 1970 ya era una de las más pobladas de la ciudad.

Así también creció el interés público y privado por transformar urbanísticamente la zona. Su localización en un área céntrica de la ciudad hizo que la idea de expulsar a los habitantes de esta villa estuviera presente en distintos gobiernos y contextos históricos. El momento más crítico fue durante la erradicación de villas efectuadas por la última dictadura militar ${ }^{6}$ en donde se desalojó de manera violenta y represiva a la mayor parte de la población de la 31. A la erradicación se sumaba el plan de construcción de autopistas que la dictadura desarrolló y que tenía un centro de conexiones previsto en el actual polígono ocupado por este barrio (Oszlak, 1991). El neoliberalismo comenzaba a implementarse en nuestro país y la reorientación de políticas urbanas con un claro énfasis en el mercado, generó fuertes consecuencias en la distribución socio-espacial. Ahora bien, la dilación en la construcción y la resistencia de decenas de pobladores organizados -junto con los de otras villas- en una "comisión de demandantes" impidió el completo desalojo de la villa de Retiro (Snitcofsky, 2012).

Con la recuperación democrática, las tierras de la villa 31-31 bis seguían siendo ambicionadas por el capital inmobiliario. El punto de mayor tensión respecto a la permanencia de la Villa 31 fue, justamente, a mediados de la década del '90 momento en que se buscó impulsar el Proyecto Retiro-Puerto (al mismo tiempo que cobraba fuerza el neoliberalismo a escala local y regional). La decisión de no implementar políticas concretas de radicación fue confluyente con planes urbanos de sesgo bien diferente a la regularización dominial (Rodríguez y Vitale, 2016). Se promovió la construcción de la autopista Illía, que implicó el desalojo de un sector de la Villa 31. En 1996, a través del Decreto $\mathrm{N}^{\circ} 110$, el intendente Jorge Domínguez dispuso el avance de topadoras para derribar las casillas allí ubicadas. La resistencia de integrantes del Equipo de Sacerdotes para Villas de la Capital Federal y la solidaridad de personalidades y organizaciones de derechos humanos obligó al Ejecutivo a buscar una salida negociada con los habitantes del barrio. El ejecutivo local logró finalizar la liberación de la traza de la autopista y sofocar el conflicto con los vecinos, pero no pudo avanzar con el Proyecto Retiro. Sin embargo, su potencial desarrollo puso en tensión 
la relación entre el Estado y los habitantes en un contexto en el que los terrenos en donde se emplaza el barrio eran ambicionados por el sector inmobiliario.

Más recientemente, en 2015, tras la asunción a los gobiernos nacional y local de dos equipos de gestión del mismo partido político ${ }^{7}$ se viabilizó la posibilidad de ejecutar el tan ansiado proyecto de renovación para la zona a través de la radicación de los habitantes de la villa y, en paralelo, el desarrollo de los proyectos Paseo del Bajo ${ }^{8}$, una nueva traza de la Autopista Illía y emprendimientos inmobiliarios de alta gama (todas obras que se impulsaron en el área circundante a la villa como el Proyecto Catalinas Norte II $^{9}$, Distrito Quartier Puerto Retiro $^{10}$, entre otros $\left.{ }^{11}\right)$. La conjunción de estas obras interviene sobre la conectividad metropolitana a partir de un reforzamiento de la centralidad de la ciudad en el eje norte-sur y se impulsa la valorización inmobiliaria a través de la construcción de grandes proyectos urbanos (GPU) y/o grandes obras de infraestructura pública (Cuenya, 2011) sobre suelo público subastado, inversiones públicas, privadas y financiamiento internacional.

Mapa 2. Proyectos de renovación urbana (Distrito Quartier Puerto Madero, Catalinas Norte II, Paseo del Bajo, Paseo de los Inmigrantes, Nueva Autopista Illía, Nueva Estación Ferrocarril Mitre) lindantes al Barrio 31-31 bis. 


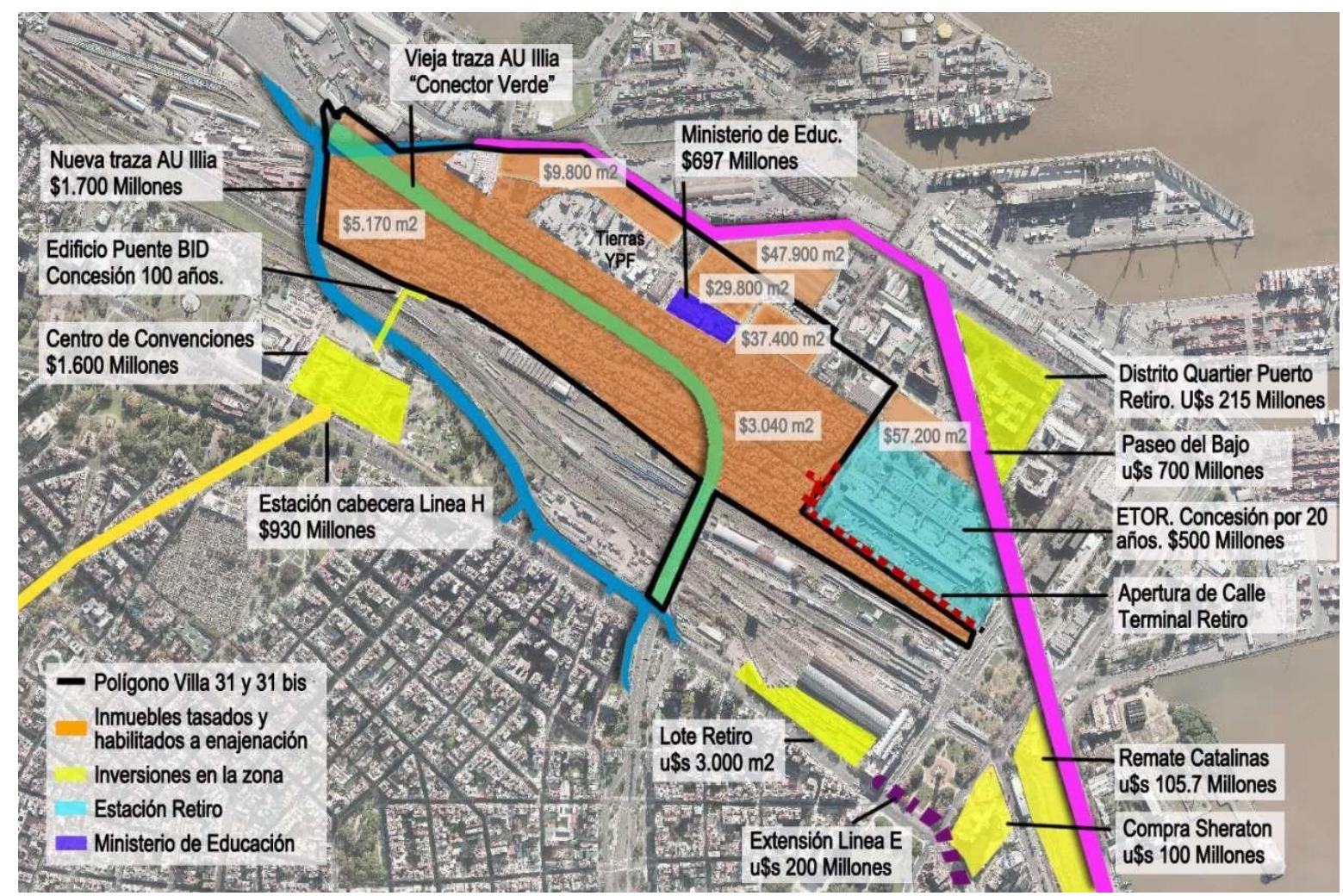

Fuente: Diagonales.com (https://bit.ly/3ab8ehT).

Como veremos más adelante, el corrimiento de la traza de la autopista Illía supone, al interior de la villa, la relocalización de 130 familias asentadas en el barrio Cristo Obrero, que ocupa parte de su nueva estructura de sostenimiento de la autopista y 1000 familias que habitan actualmente debajo de la traza actual de la autopista vieja, que se convertirá en un gran corredor verde de escala urbana, con actividades recreativas y fuerte conexión de transporte público para el conjunto de la ciudad. En el mapa anterior puede observarse que los proyectos de la Nueva Autopista Illía (evaluada por muchos especialistas como “innecesaria”) y el Paseo del Bajo bordean, encorsetan y ponen límites al crecimiento y expansión de la producción social de la villa.

Los proyectos orientados a la revitalización y puesta en valor de la zona de Retiro contextualizan la intervención urbana del GCBA sobre la Villa 31-31 bis.

\section{La Re-urbanización de la villa: el Plan de Soluciones Habitacionales}

El proyecto contempla tanto la construcción de viviendas nuevas como la 
recuperación de viviendas deficitarias. En relación a las primeras, estas tienen por objetivo la relocalización de unidades habitacionales irrecuperables por sus condiciones de habitabilidad o porque su ubicación exige el traslado de las familias residentes. Actualmente en la villa 31 y 31 bis se identifican 2 proyectos de relocalización.

Mapa 3. Zonas a reasentar y localización de viviendas nuevas YPF y Containera.

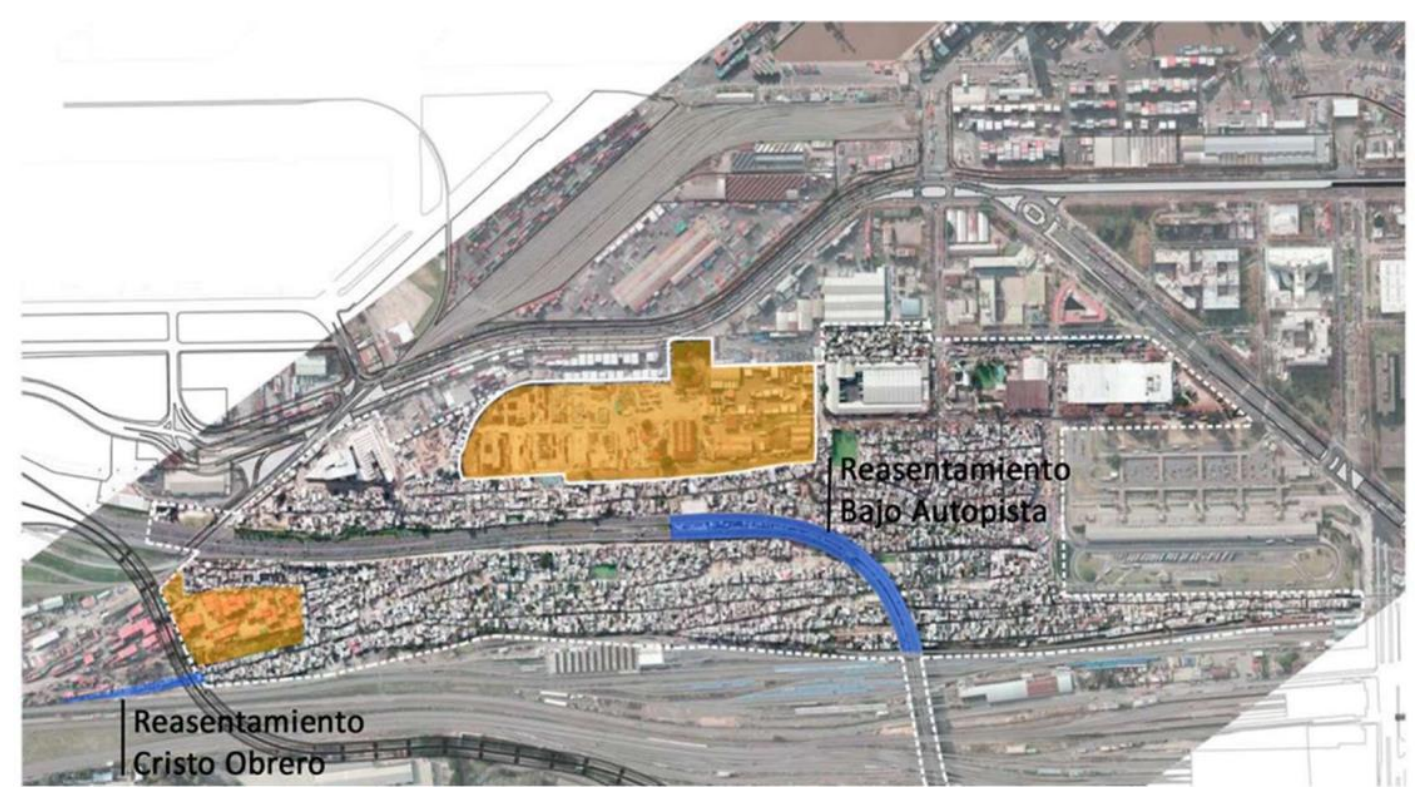

Fuente: Secretaría de Integración Social y Urbana -SISU-, GCBA (2017).

El primero de ellos destinado a las familias asentadas en la zona de Bajo Autopista que serán trasladas a un nuevo terreno, lindero, recientemente adquirido por el gobierno local. El Barrio YPF, donde estarán estas familias relocalizadas, tiene 33 edificios en los que se distribuyen 1032 unidades habitacionales que anunciaron serán entregadas en febrero de 2019. Se tratan de complejos de Planta baja y 3 pisos en altura en los que hay unidades funcionales de 2, 3 y 4 ambientes, de uso exclusivo residencial, comercial y social, y también de uso mixto. El segundo proyecto de relocalización es el de las familias asentadas en las manzanas 12 y 104 del barrio Cristo Obrero afectadas por la traza de la Nueva Autopista Illía, quienes comenzaron a ser trasladas a los terrenos linderos, llamados Containera. El proyecto de viviendas nuevas Containera consta de la construcción de 5 edificios en los que se distribuyen 161 unidades funcionales (viviendas y locales) de las cuales ya se entregaron 
39 unidades habitacionales en diciembre de 2017 (familias base del trabajo de campo realizado). Se trata de edificios de empalque con planta baja y 2 plantas altas y edificios de viviendas agrupadas de planta baja y 3 pisos en altura, con departamentos 2, 3 у 4 dormitorios. Las obras de ambos proyectos son ejecutadas por grandes empresas constructoras habituadas a trabajar con el Estado y los destinatarios de las unidades habitacionales nuevas involucran tanto a propietarios e inquilinos de la zona afectadas.

A partir de la existencia en la villa de gran cantidad de trabajadores que se dedican a ser obreros de la construcción, desde el Programa inicialmente se estableció que muchos de ellos serían absorbidos por las empresas constructoras para la construcción de las viviendas, pero esto se ha concretado de manera muy acotada dando cuenta de un total desaprovechamiento de las capacidades constructivas existentes en el barrio.

Imágenes 1 y 2. Render proyectos de YPF y Containera. Villa 31 y 31 bis

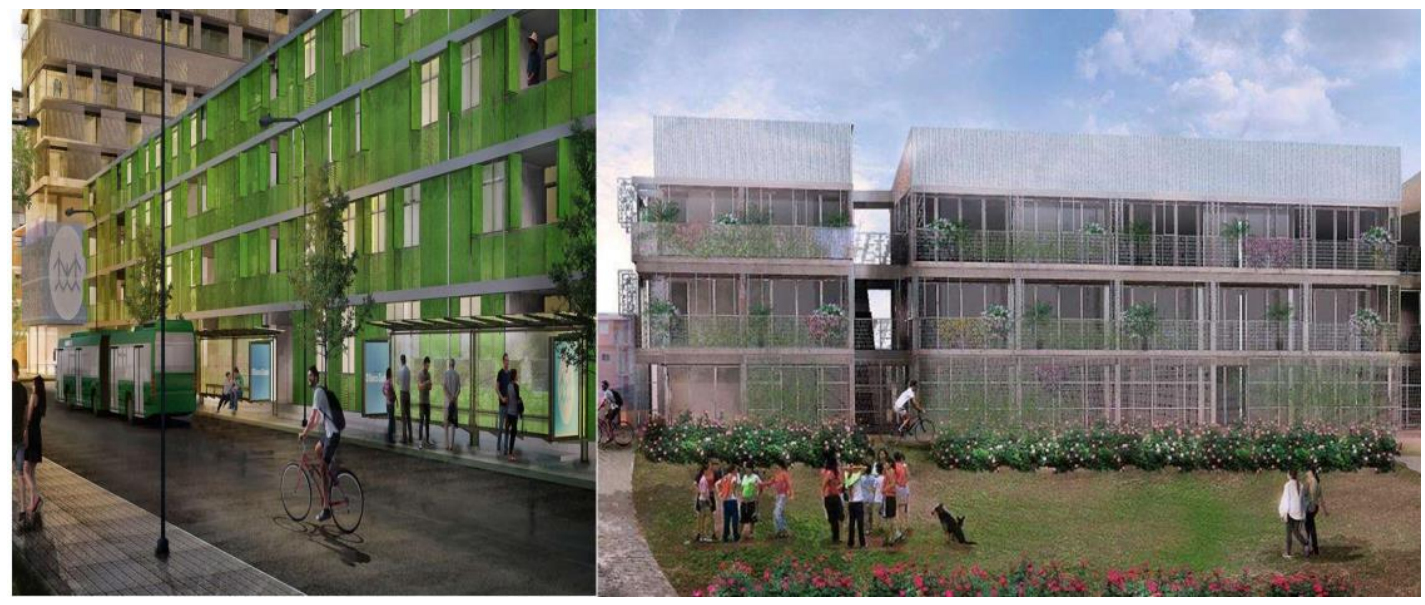

Fuente: Secretaría de Integración Social y Urbana, GCBA (2017).

Gran parte de las obras de la Containera se encuentran finalizadas, en diciembre de 2017 comenzaron las entregas de las viviendas a sus adjudicatarios y continuaron a lo largo del 2018. Las obras de YPF comenzaron a ser entregadas a inicios de 2019. Es imperioso señalar que la ejecución de estos proyectos constructivos y el habitar de las viviendas nuevas por los adjudicatarios se desarrollaron con alto nivel de conflictividad a escala territorial.

Por su parte, el Programa de Mejoramiento de Vivienda tiene por objetivo consolidar 
la morfología del barrio existente, a partir de la rehabilitación de aquellas viviendas localizadas en el macizo de la villa que resultan recuperables. Para ello, la SISU realiza un diagnóstico en las viviendas mejorables para identificarlas con necesidad de intervención baja, media o alta. Al interior de las mismas se prevén obras de terminaciones, infraestructura sanitaria y eléctrica, modificaciones en la configuración interna de las viviendas, ventilación e iluminación y obras de conexión a infraestructura de servicios públicos (eléctrica, sanitarias y pluviales), ejecutadas por cooperativas del barrio. En el exterior se realizan obras de terminaciones, aislaciones, mejoramiento de terrazas y fachadas, y obras de seguridad y accesibilidad, ejecutadas por empresas/contratistas privadas vías licitación pública. La ejecución de este componente del programa se inició en 2016 a partir de una prueba piloto en un manzana lindera a la autopista 25 de Mayo, para evaluar allí el funcionamiento del programa y las posibilidades de escalamiento del proyecto. Su ejecución fue conflictiva, produjo desalojos de familias inquilinas, alentó el incremento desregulado de precios hacia los nuevos inquilinos, generó descontento por los criterios de selección entre beneficiarios, tuvo costos elevados que no se hicieron públicos, etc.

Imágenes 3, 4, 5 y 6 . Antes y después de obras de mejoramiento internas y externas a la vivienda. Villa 31 y 31 bis. 

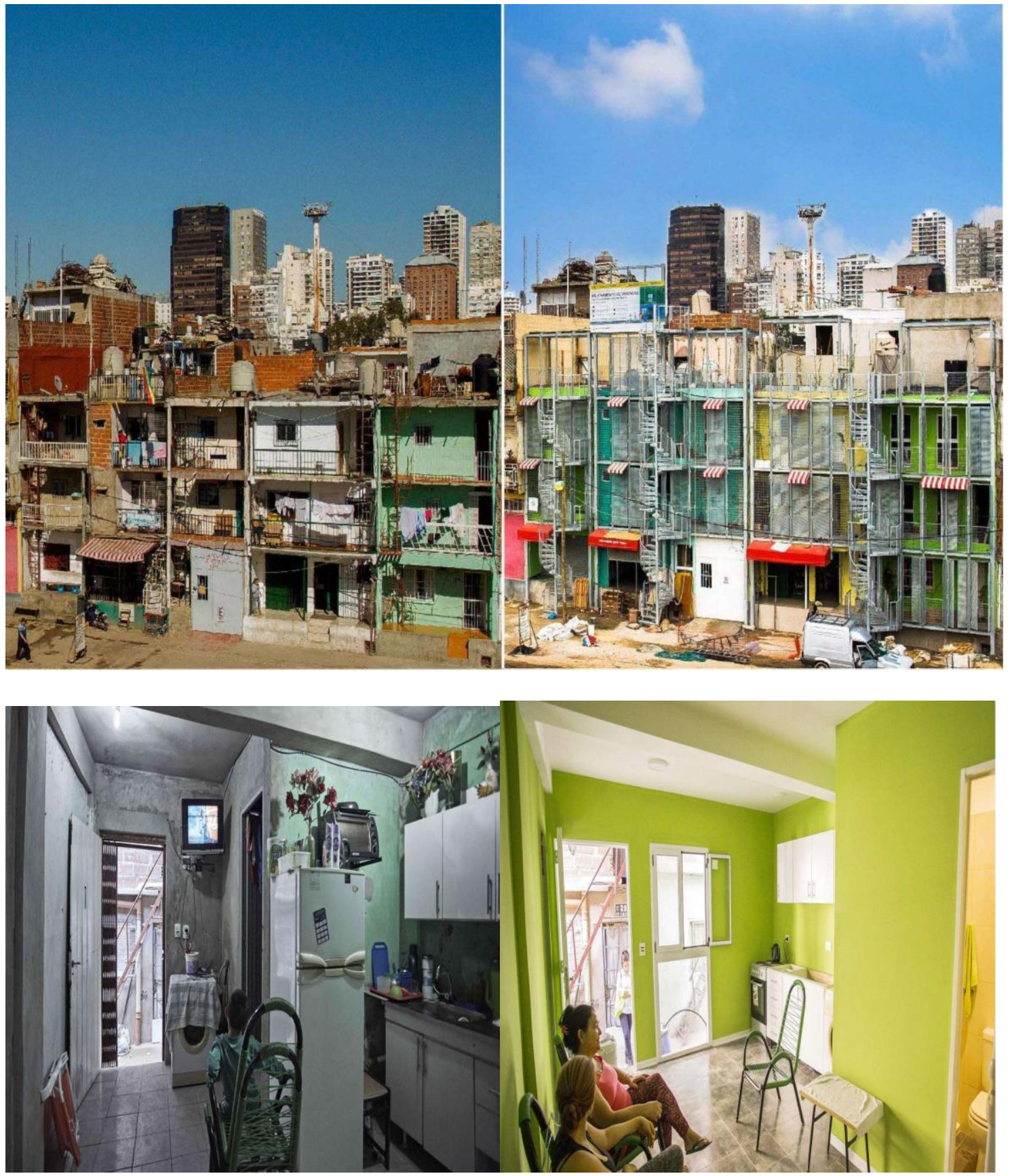

Fuente: Secretaría de Integración Social y Urbana. GCBA (2017).

Por último, es importante señalar que las obras de vivienda nueva avanzaron a una velocidad superlativa en relación a las obras de mejoramiento de las viviendas del macizo, lo que da cuenta de una ejecución de las políticas en distintas velocidades en función del componente que trate. 


\section{Participación y conflicto en Villa 31-31 bis: formatos participativos de la villa}

La Villa 31 y 31 bis se encuentra atravesada por numerosos y sucesivos procesos organizativos que se extendieron a lo largo de su historia y que han tenido un peso significativo en su desarrollo y evolución. En la actualidad estas trayectorias participativas se plasman en diferentes organizaciones de base territorial que se organizan alrededor de tres Mesas de Urbanización: 1) la Mesa Histórica (surgida alrededor del año 2005 como resultado de la interacción con la Facultad de Arquitectura y Urbanismo de la Universidad de Buenos Aires para la formulación de la que posteriormente fue la Ley de Urbanización de la Villa. Esta mesa actualmente nuclea fundamentalmente a referentes históricos de la villa como Teófilo Tapia, Carlos Cuenca, Aida Campo y otros); 2) la Mesa Disidente (la cual nace como un desprendimiento de la Mesa Histórica aproximadamente en el año 2016, tras la llegada al barrio de la SISU y en el marco de los debates desarrollados por el dictamen del Proceso de urbanización que enfrenta actualmente el barrio.) y 3) la Mesa por la Urbanización Participativa y Rotativa de la Villa 31 y 31 bis (que emerge como consecuencia del proceso de reurbanización por vecinos del barrio en disidencia con el modo de actuación de las otras mesas en la articulación con el GCBA. Esta mesa de autoconvocados cuestiona fuertemente la actual reurbanización considerándola una "pantalla" tras los negocios inmobiliarios que se proyectan en la zona y los intereses de mercado que propiciarían a futuro la privatización de esas tierras. Entre sus reclamos señalan la importancia de impulsar la urbanización a través de una participación "real" en la que se respeten los principios de la ley № 3343).

Revisando la gestación de la institucionalidad que enmarca el proceso de urbanización, se reconoce que las normativas que hoy atraviesan y regulan el funcionamiento del barrio fueron elaboradas de manera estrictamente participativa. La Ley $\mathrm{N}^{\circ} 148$ sancionada en el año 1998, tuvo lugar en el marco de un inédito proceso participativo de gran parte del campo villero de la ciudad y dio origen al Programa de Regularización, Integración y Transformación de Villas y Núcleos Habitacionales Transitorios (PRIT) orientada a la radicación de todas las villas de la Ciudad de Buenos Aires. Específicamente la villa 31 y 31 bis cuenta con la ley $\mathrm{N}^{\circ} 3343 / 09$, la cual tuvo sus orígenes en un recurso de amparo colectivo presentado por los vecinos con apoyo de un legislador porteño, pero que 
dio inicio e impulso a un fuerte proceso de discusión social hacia el interior del barrio sobre la regularización de las elecciones de autoridades y el proyecto de urbanización del barrio.

No obstante esta densa trayectoria participativa pre-existentes del barrio, lo que nos interesa analizar en este artículo son las instancia de participación social generadas por la SISU en el marco del Programa de Soluciones Habitacionales del Proyecto de Reurbanización del barrio y si se reconoce algún tipo de recuperación de estas trayectorias precedentes.

En este sentido, las estrategias de participación social desplegadas en el barrio por parte de la SISU fueron numerosas y adoptaron diversas tipologías. Estas instancias se caracterizaron por tratarse de reuniones, talleres, buzones de consulta, encuestas, recorridas observacionales, etc., todas coordinadas de manera vertical por los equipos sociales de la propia secretaría. Las mismas desarrollaron una gran diversidad temática, que trataron desde cuestiones vinculadas a las obras de espacio público, especificidades de los programa de Mejoramiento de Vivienda y Vivienda Nueva, entre otras cuestiones vinculadas estrictamente a la urbanización, como espacios de discusión sobre problemáticas sociales que afectan a los pobladores del barrio: como cuestiones de género, adicciones, sexualidad, etc. Estas instancias participativas se organizaron por sector, manzana o grupo dependiendo de la temática a trabajar y con distintas frecuencias (semanal, quincenal o mensual). También, la secretaría contó con un plantel de trabajadoras sociales que realizaron un trabajo de acompañamiento familiar (desde un abordaje individual) y de emergencia y desarrolló talleres de fortalecimiento orientado a organizaciones sociales del barrio. Incluso, es significativo para el análisis señalar que el propio organismo en sus informes de gestión para los organismos internacionales debe reportar los avances conseguidos en el diseño e implementación de la política participativa y cuantificar a partir de un conteo riguroso la cantidad de reuniones convocadas y de la asistencia de vecinos por reunión (SISU, 2017 en Capalbo, 2019a).

No obstante este derrotero, y el reconocimiento formal de designaciones de consejeros previstos por ley y una trama sofisticada de múltiples instancias y niveles de interpelación vecinal, el producto de dicho entramado distó de aportar a la posibilidad efectiva de toma de decisión de los vecinos sobre cuestiones que afectan a la re-urbanización de su barrio ${ }^{12}$. Más bien proliferaron las reuniones consultivas o de tinte informativo 
orientadas a la validación social de las distintas intervenciones del proyecto de reurbanización. Las tomas de decisiones fueron acotadas, involucraron decisiones tales como definir el nombre de una plaza o el color con el que se pintarán los juegos infantiles o las fechadas de las viviendas. Por lo que los vecinos del barrio -ni siquiera a través de sus instancias colectivas y organizadas- pudieron incidir en decisiones tales como los materiales constructivos de las viviendas nuevas o los mejoramientos, sus diseños, la distribución de los espacios, los actores que intervienen en el proceso productivo, entre otras cuestiones estructurales a un proyecto de integración social y urbana. Es importante señalar que estos espacios de participación vinculados estrictamente a la gestión del proceso de reurbanización tampoco previeron formas de articulación con el entramado organizativo preexistente y enfatizaron, por el contrario, un abordaje de las distintas problemática totalmente individualizante.

Específicamente en relación al Programa de Realojamiento en Vivienda Nuevas, a partir del trabajo de campo realizado en el barrio y los testimonios recolectados pudo identificarse un alto nivel de incertidumbre por parte de los vecinos afectados, tanto de Bajo Autopista como de Cristo Obrero, sobre sus destinos habitacionales y económicos. Todos los entrevistados contaban con la certeza que iban a ser realojados en las viviendas nuevas por estar las suyas afectadas por obras de interés general, pero no tenían conocimiento ni fueron informados sobre especificidades de sus nuevas viviendas, como por ejemplo, si se localizarían en planta baja o alta y si esto pudiera comprometer sus medios económicos de subsistencia. Si bien en el censo que realizó la SISU se relevaron las necesidades de unidades funcionales con uso mixto (residenciales y productivas), los vecinos desconocían si sus actividades económico-productivas iban a ser contempladas o no por los arquitectos proyectistas y esto repercutió en un fuerte malestar social. Incluso también existió un fuerte nivel de incertidumbre en relación al esquema de pago de dichas viviendas, pues se identificó un temor generalizado vinculado principalmente a la imposibilidad de sostenimiento de una deuda hipotecaria por un plazo de décadas ante contextos laborales de alta informalidad y precarización característicos de la población de este barrio y frente al proceso hiperinflacionario que vive nuestro país (sólo el año 2018 tuvo una inflación acumulada del 47,6\% -la más alta desde 1991- y el aumento en gastos de vivienda, agua, electricidad, gas y otros combustibles representó un 45,7\% (Indec, 2019)). 
Otro de los factores que generó rechazo a los realojamientos se vincula con la imposibilidad de crecimiento en altura que poseen las viviendas en tipología de departamentos para futuros desgloses familiares. La tenencia de un terreno libre en altura y las habilidades constructivas que tienen los pobladores de la villa funcionan en la reproducción de vida cotidiana de las familias como un resguardo ante las recurrentes crisis económicas de nuestro país, el crecimiento y/o desdoblamiento familiar y la imposibilidad de acceso a una vivienda en propiedad, estrategia totalmente abortada a partir de la aceptación de las nuevas viviendas. Las familias perciben la aceptación de las nuevas viviendas como un estrechamiento de las posibilidades de reproducción cotidiana de sus vidas y la de sus hijos en el mediano y largo plazo.

Las calidades constructivas de las nuevas viviendas también se configuraron como un factor de conflicto en este proceso. Las nuevas construcciones en curso tratan de estructuras edilicias (vigas y columnas) de material de hormigón armado combinadas en sus intersticios con paneles de fibra de madera aglomerada o yeso (conocidas comercialmente como OSB o durlock) que habilitan un tipo de construcción en seco (también llamado steel framing). Esta metodología constructiva se utilizó en los muros interiores, en los divisorios entre las diferentes unidades habitacionales y en los exteriores, los cuales fueron revestidos con chapa de color azul. Estas formas de construcción resultan más económicas y rápidas (en términos que no necesita revestimiento y reduce gastos de terminaciones e instalaciones) pero niegan la trayectoria constructiva del barrio (gran parte de las viviendas fueron autoproducidas completamente con métodos tradicionales de construcción a partir de esfuerzo, ahorro y trabajo de las propias familias) y además niega la expertise de la cuantiosa cantidad de albañiles que residen en el barrio. Tras la visita de los vecinos de las manzanas 104 y 12 a las viviendas nuevas localizadas en Containera, en el marco de una actividad convocada por la misma SISU el primer fin de semana de octubre de 2017, generó un alto nivel de malestar entre los habitantes tras verificar las calidades constructivas de las nuevas unidades habitacionales. Esta disconformidad colectiva llevó a numerosas expresiones de rechazo y protesta por parte de los vecinos que exigen en las nuevas viviendas iguales calidades constructivas a las autoproducidas. Estas expresiones de descontento se extendieron durante todo 2018 con diferentes escalas de conflictividad. 
Imagen 7: Protesta de destinatarios de vivienda nueva tras visita a las unidades habitacionales. Containera, Villa 31-31 bis.

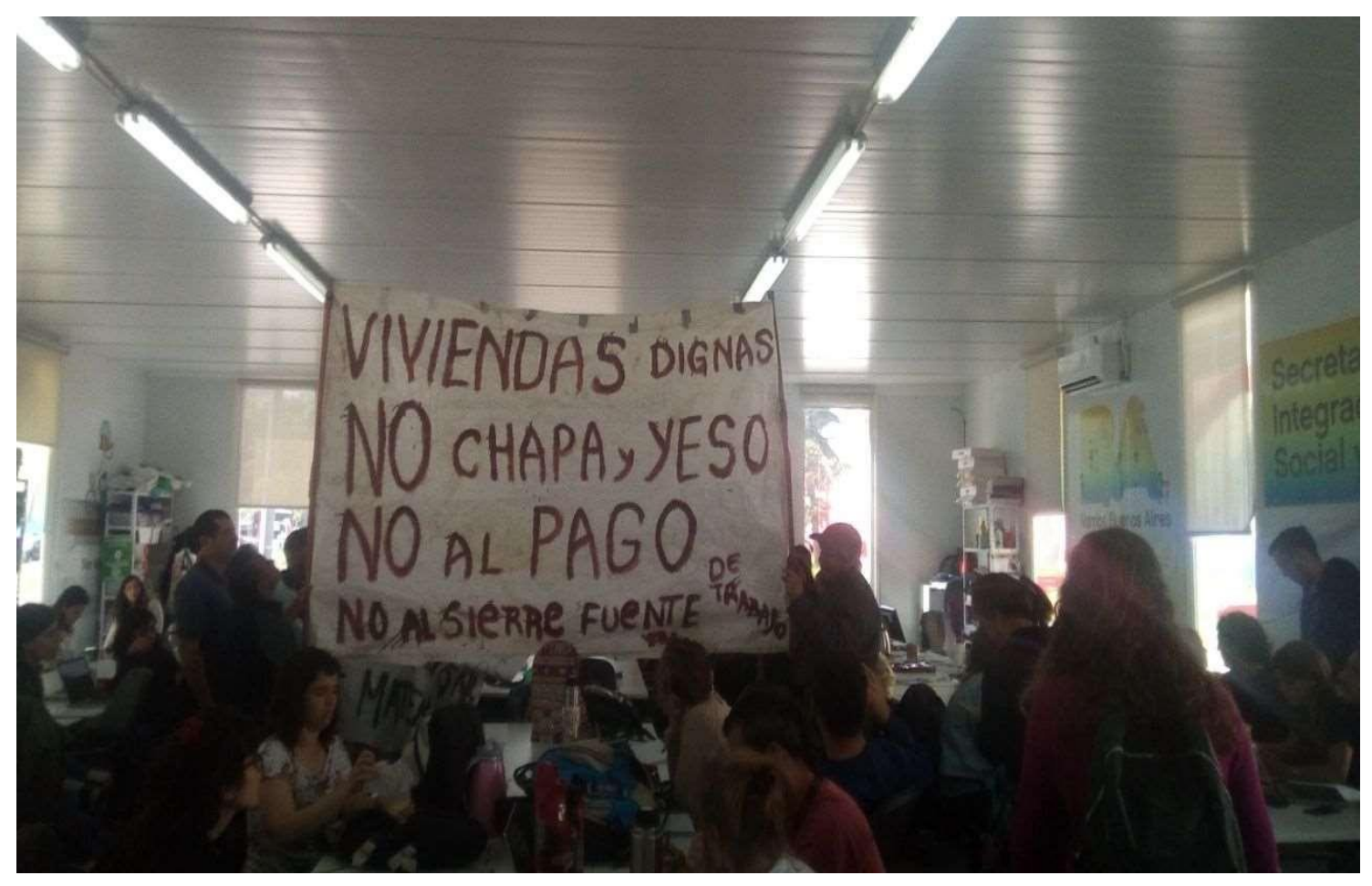

Fuente: Fotografías tomadas por vecinos en visita a las viviendas realizada el 7/10/2017.

Evidentemente el material constructivo de las viviendas tiene un alto peso simbólico para las familias residentes de la villa. El haber transitado experiencias traumáticas de hábitat en viviendas de cartón o chapa, en pésimas condiciones de habitabilidad, las unidades habitacionales de yeso y chapa ofrecidas actualmente por el Estado fueron percibidas por los vecinos como un retroceso en su calidad de vida (por más que quizás técnicamente la construcción en seco de las nuevas viviendas sean una opción viable). Esta incongruencia entre las soluciones aportadas por el Estado y los gustos y necesidades habitacionales de las familias destinatarias habla de la falta de canales reales de participación social.

En este sentido, una vecina comentaba en una de las entrevistas realizadas: "Son viviendas para pobres" [Vecina inquilina realojada de manzana 104 a Containera. Villa 31 bis. CABA. Septiembre 2017]. Asimismo, un comunicado emitido por la población de esas manzanas el 17 de Octubre de 2017, señala que "pretenden darnos casas de materiales muy inferiores a las que hoy tenemos y con mucho menos espacio" y exige "queremos mudarnos 
TODOS JUNTOS, queremos que respeten la cantidad de metros y la calidad de construcción que hoy tienen nuestras viviendas". El documento aclara también que "Nadie nos consultó si queríamos una autopista encima de nuestras cabezas, nadie nos consultó cómo sería la mejor forma para llevar esta relocalización, nadie nos consultó si nos queríamos ir, ni siquiera si estábamos dispuestos a irnos", evidenciando serias falencias en los dispositivos de 'participación' generados por el GCBA en el barrio.

En relación a esto, la preocupación de los realojados a las viviendas nuevas se vincula a la forma de mantenimiento y costos de manutención de los edificios, pues este tipo de construcciones en seco requieren de un mantenimiento mayor que viviendas construidas con materiales tradicionales de construcción. La obra tiene garantía por un año con las empresas constructoras que intervinieron en las construcciones, pero tras su partida serán las mismas familias las que deberán proveer el mantenimiento de los complejos en un escenario en el que estarán devolviendo el crédito hipotecario de las viviendas. Este hecho demuestra un claro desajuste entre lo unilateralmente construido por el Estado y las preferencias, necesidades y realidades económicas de los destinatarios. Pues una técnica constructiva que genere los menores gastos de mantenimiento posterior hubiera sido quizás más acertada.

Imágenes 8, 9 y 10. Fotografías de las viviendas nuevas construidas en Containera. Villa 31 bis. Paredes internas y divisorias de departamentos en yeso seco y paneles externos de chapa.

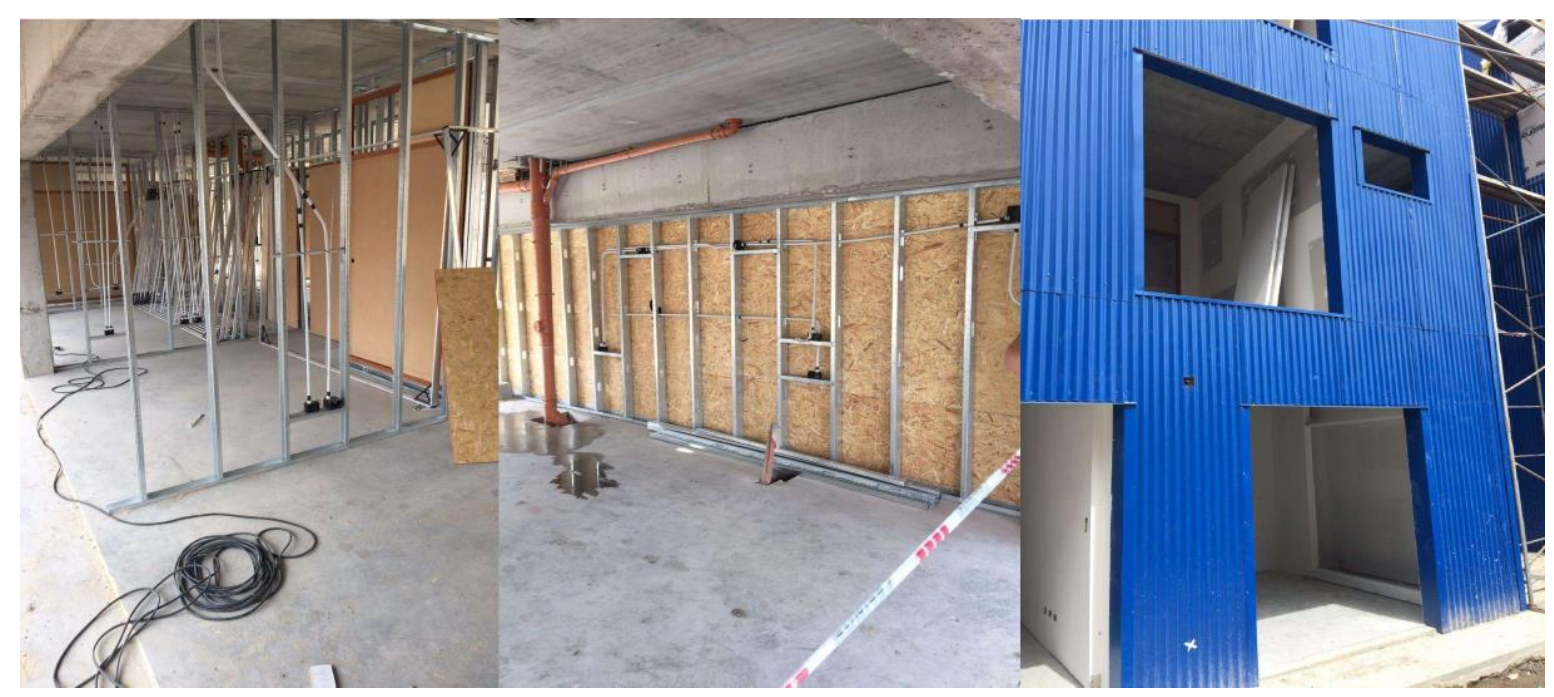

Fuente: Fotografías tomadas por vecinos en visita a las viviendas nuevas realizada el $7 / 10 / 2017$. 
También existe una fuerte intranquilidad vinculada a la reproducción de actividades económicas minoristas realizadas por muchas familias en sus hogares (el ejemplo más común es mini-kiosco de venta de algunos productos específicos como gaseosas). No existen definiciones claras de cómo -tras el realojamiento- estas familias podrán continuar realizando dichas actividades (que en muchos casos representan sustentos de vida cotidiana).

En relación al Programa de Mejoramiento de Vivienda, como se dijo anteriormente se desarrollaron experiencias piloto de mejoramientos en la manzana G1. Si bien es cierto que dichas obras redundaron en una mejora en la calidad de habitabilidad de las viviendas por parte de los destinatarios, el ensayo realizado por la SISU también dejó algunas cuestiones a prestar atención.

En primer lugar, este ensayo piloto no tuvo la previsión de contemplar la existencia de inquilinos en las parcelas a mejorar redundando en un proceso de desalojo compulsivo de inquilinos por lo propietarios a fin de ser "elegibles" como destinatarios del programa de mejoramiento. Adicionalmente no se vaticinaron las consecuencias que los mejoramientos pueden tener en los valores del alquiler (incluso a escala barrial) una vez renovadas y mejoradas las condiciones de habitabilidad de las viviendas. Pues existe una alta probabilidad que los propietarios con habitaciones en alquiler recicladas aumenten sus precios descargando en los inquilinos (una de las poblaciones más vulnerables del mercado habitacional informal del barrio) parte del crédito que estos tienen que devolver en concepto de las obras realizadas. Vale aclarar que todavía no hay definiciones certeras del crédito al que serán afectadas las familias receptoras del plan de mejoramiento.

Por otra parte, en el trabajo de campo realizado se registraron numerosas quejas de vecinos acogidos al programa por la precaria calidad constructiva de los mejoramientos realizados y la dilación en el tiempo de ejecución de las obras. Algunos vecinos nos plantearon que en sus viviendas, al ser objeto de una reconfiguración interna de los espacios, se demolieron paredes de material concreto que luego fueron reconstruidas en seco con paneles de durlock recubiertos de yeso, repercutiendo en una precarización de la calidad constructiva de sus viviendas. Evidentemente la modalidad constructiva empleada mediante el Programa de Mejoramiento de Vivienda es el mismo que el ejecutado en las viviendas nuevas, con las mismas repercusiones a nivel social. Si bien las viviendas recicladas ofrecen 
una mejor calidad de vida para sus habitantes, los entrevistados perciben en estas obras una precarización de la calidad de sus viviendas. También se registraron quejas vinculadas a la paralización de las obras de mejoramiento por la falta de acuerdos con vecinos por la apertura de espacios de ventilación y/o corrimiento de escaleras. Incluso se verificaron algunos descontentos que decantaron en procesos de judicialización hacia la SISU.

Ahora bien, en paralelo a este proceso participativo, entre julio de 2017 y diciembre de 2018 se desplegó desde la SISU un proceso participativo para la elaboración del dictamen de la Ley $\mathrm{N}^{\circ} 3343$. La Mesa de Trabajo para el dictamen estuvo conformada por dos mesas coordinadas verticalmente desde la secretaría: 1) inicialmente, la Mesa Técnica en la que participaron referentes profesionales, organizaciones no gubernamentales vinculadas a la temática villera y las distintas Defensorías organizados en comisiones y plenarios; y 2) luego, la Mesa abierta al barrio en la que intervinieron organizaciones sociales del barrio y referentes históricos, consejeros, cuerpos de delegados y representantes de las Mesas de urbanización y cooperativas y vecinos agrupados por sector. Si bien este proceso participativo recuperó la trayectoria histórica de organización social de base de la villa y logró un cierre en diciembre de 2018 con la sanción por parte de la legislatura porteña del mentado dictamen, el nivel de conflictividad con el que se desarrolló la mesa de trabajo fue muy alto. Las expresiones de descontento por parte de diversos sectores del barrio se expresaron en diversas manifestaciones frente a las oficinas estatales localizadas en el barrio, marchas semanales en distintos barrios de la villa y dentro y fuera de la Legislatura en las sesiones de presentación y audiencia pública del proyecto de dictamen $\left(\mathrm{N}^{\circ} 2736 / 18\right)$.

Imágenes 11 y 12. Manifestaciones de pobladores de la Villa 31-31 bis en rechazo al Dictamen $N^{\circ} 2736 / 18$ frente a la Legislatura Porteña y al portal de la SISU en el barrio.

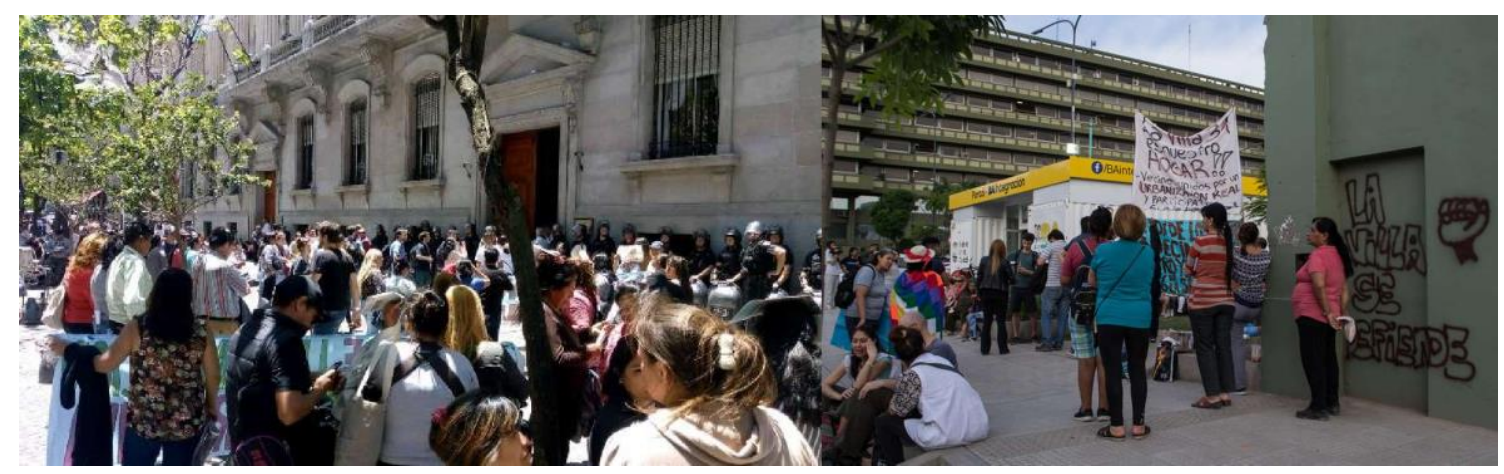


Fuente: Fotografías tomadas por participantes de la Mesa de urbanización participativa. $12 / 2018$.

Incluso la sesión de votación del dictamen sólo pudo desarrollarse con un muro policial frente al palacio legislativo que impidió el ingreso al recinto de muchos de los vecinos disidentes. Estos conflictos desarrollados a escala territorial ponen en fuerte cuestionamiento las instancias participativas diseñadas para la elaboración del dictamen y su consecuente nivel de legitimación.

\section{Conclusiones}

A lo largo de estas páginas se analizó la estrategia de participación social implementada por el gobierno local en el marco de la intervención de Soluciones Habitacionales contemplada en el Proceso de Re-urbanización de la Villa 31-31 bis de la Ciudad de Buenos Aires a partir del año 2016 hasta inicios de 2019.

Siguiendo con los autores citados y a la luz del trabajo de campo realizado, este análisis verificó que la ejecución del proyecto de reurbanización se desarrolló con un significativo nivel de conflictividad a nivel territorial y que las estrategias y dispositivos de participación desplegados, se focalizaron hacia la desactivación de dicha conflictividad, buscando invisibilizar y acotar la capacidad de agencia del entramado de organizaciones sociales preexistentes, mediante una activa política de cooptación selectiva, ignorancia del resto y una densa trama de consultas vecinales individualizantes y de acotada significación.

A pesar de las numerosas instancias de participación construidas para la implementación del proyecto, los testimonios recolectados identificaron un alto nivel de incertidumbre por parte de los vecinos afectados, tanto de Bajo Autopista como de Cristo Obrero, sobre sus destinos habitacionales y económicos. Así también altos niveles de disconformidad vinculados con las metodologías, materiales, diseños y calidades constructivas de las viviendas nuevas e incertidumbre sobre las posibilidades de mantenimiento posterior de los complejos. Las metodologías constructivas utilizadas por la SISU resultaron más económicas y rápidas (en términos que no necesita revestimiento y reduce gastos de terminaciones e instalaciones) pero negaron las preferencias constructivas 
de sus futuros habitantes, la trayectoria constructiva del barrio (gran parte de las viviendas fueron autoproducidas completamente con métodos tradicionales de construcción a partir de esfuerzo, ahorro y trabajo de las propias familias) y la expertise de una cuantiosa cantidad de albañiles que residen en el barrio. Otro de los factores que generó rechazo a los realojamientos se vincula con la imposibilidad de crecimiento en altura que poseen las viviendas en tipología de departamentos para futuros desgloses familiares. Todas estas cuestiones generaron malestares que se expresaron a diciembre de 2017 en protestas y movilizaciones por parte de los vecinos que exigieron en las nuevas viviendas iguales calidades constructivas a las autoproducidas.

En paralelo a esta operación territorializada, en el plano de la elaboración normativa se estructuró un proceso participativo para legitimar la sanción del nuevo dictamen de la Ley 3.343 de radicación del barrio, sin embargo lejos de eso, dicha sanción tuvo lugar gracias a un cordón policial que bloqueó las expresiones de descontento y desaprobación de los vecinos del barrio.

Estos conflictos dieron cuenta que la existencia de instancias de participación social en la ejecución de una política no son garantía per sé de que todos los actores tengan el mismo peso en la toma de decisiones (Zapata, 2017). Los espacios participativos creados distaron de ser instancias de real toma de decisión por parte de los destinatarios de la política, para dar cuenta más bien de procesos de falsa participación (Pelli, 2007) social. Recuperando el marco teórico de análisis de este artículo, estas instancias asumieron una tipología clientelista (De la Mora, 2002), en las que se generó una dinámica de relegitimización de la dominación política y una invisibilización del estrecho vínculo de intereses que existen entre el Estado (neoliberal) y el mercado. Las distintas herramientas, instrumentos y técnicas desplegadas por la nueva gobernanza urbana remiten a prácticas de legitimación de una política habitacional que implícitamente buscó la valorización de la ciudad neoliberal. Pues la introducción de estrategias participativas, lejos de construir instancias de consenso que redunden en la reducción de la desigualdad socio-urbana de las ciudades, estuvieron asociadas a la ejecución de grandes proyectos urbanos y/o grandes obras de infraestructura orientadas a la dinamización económica de la ciudad, en donde la nueva gobernanza urbana y la retórica participativa funcionaron como estrategias de legitimación de tal proceso de mercantilización de esta zona de la ciudad. 
El caso de análisis, entonces, permite reflexionar sobre los límites de un proceso participativo en un escenario de gobernanza urbana donde las leyes neoliberales del mercado se configuran como sostén del proceso de mercantilización del suelo. La noción de gobernanza urbana omite las relaciones desiguales de poder que existen entre los distintos actores que conforman esa gobernanza (estado -en sus distintos niveles e institucionalidades-, mercado -en sus distintos perfiles: desarrolladores, comercializadores, etc.- y la sociedad civil -en su heterogeneidad organizativa-). La invisibilización de la disputa de poder entre diversos actores en los procesos de toma de decisión que habilitan las instancias de participación, generó que en estos procesos, se termine favoreciendo los intereses de aquellos actores con mayor peso relativo y capacidad para transformar la ciudad (De Mattos, 2008). Además, el rol de promotor de estas instancias de participación de las que se apropia el Estado local, esconde la verdadera función que desempeña este actor en estos procesos de transformación urbana. Pues el Estado no es un actor neutral en el proceso de reurbanización y renovación que se impulsa en la villa 31 y 31 Bis y las zonas aledañas, sino que además de desempeñar un rol subsidiario a los intereses del sector inmobiliario, desempeña un rol estratégico, prefigurativo y determinante para poner en marcha el proceso de valorización del suelo y renovación urbana en esta zona de la ciudad. Por lo que las instancias de participación construidas a escala territorial funcionan -con gran pragmatismocomo dispositivo de legitimación social del proceso de valorización del barrio y sus aledaños.

No obstante esto, en barrios con trayectorias participativas tan arraigadas como lo es la trayectorias organizativa de la villa 31 y 31 Bis, si la divergencia de intereses no logra ser canalizada mediante las instancias de participación institucionalizadas estatalmente, estas se expresan mediante la protesta, y por ende el conflicto, en tanto única forma de expresión del desacuerdo.

Este análisis permite dar cuenta entonces de un déficit estructural de la política actual que tiene que ver con una concepción desarticulada de una política habitacional integral. Los únicos procesos de reurbanización en curso en la Ciudad de Buenos Aires están asociados a proyectos de renovación o Grandes Proyectos Urbanos que tienden a encarecer el precio de la tierra y alentar la especulación inmobiliaria, incentivando una dinámica excluyente en términos del acceso a la tierra y la vivienda para los tradicionales habitantes de estos barrios. 
Pero además tampoco se han considerado mecanismos orientados a regular el mercado del suelo (que muchos países 'desarrollados' implementan) que permitan frenar los efectos nocivos que su libre funcionamiento produce en relación al acceso a la vivienda y en cuyo marco se constituyen y reproducen las villas, entre otras formas del déficit habitacional. De esta manera, aunque avanzar en la reurbanización de estos barrios es sin dudas positivo, también hay que señalar la necesidad de alcanzar una mirada más integral con respecto al suelo y la vivienda para avanzar en una lógica real de acceso al hábitat de calidad, y el reconocimiento de las familias como "sujeto colectivo" en el derecho a la ciudad.

\section{Notas}

${ }^{1}$ La Región Metropolitana de Buenos Aires (RMBA) está integrada por la Ciudad Autónoma de Buenos Aires y los 43 partidos de la provincia de Buenos Aires, representando el mayor conglomerado del país con una extensión de $11.500 \mathrm{~km} 2$ y más de 16 millones de habitantes (el $44 \%$ de la población total).

2 El Proyecto de Re-urbanización del barrio prevé intervenciones orientadas a la cuestión habitacional, pero también hacia un mejoramiento de la infraestructura urbana (apertura de calles, tendido de infraestructura de servicios públicos, pavimentación de aceras, iluminación, etc.) e intervenciones de conectividad urbana (obras viales que intervienen en la conectividad metropolitana, multiplicación de ingresos-egresos al barrio). Esta intervención comienza con la gestión de Horacio Rodríguez Larreta, Jefe de Gobierno de la Ciudad de Buenos Aires desde el 2015 al presente.

${ }^{3}$ Dicha encuesta se realizó en el marco del mencionado Proyecto PICT 2015/1491 en los barrios Villas 31 y 31 bis, Rodrigo Bueno, la villa 21-24, villa 20 y villa 3-Fátima, donde se realizaron 304 encuestas para indagar las características que asumió en mercado informal de alquiler.

${ }^{4}$ El debate sobre la noción de nueva gobernanza es extenso y cuenta con diversos enfoques (ver Aguilar Villanueva, 2006; Zurbriggen, 2011). No obstante, retomando a estos autores, aquí sólo se referenciará que existen dos corrientes dominantes dentro de las ciencias políticas: a) la escuela de las redes de políticas públicas que focalizan la atención en la concertación de intereses entre diversos actores públicos o privados para la elaboración de políticas públicas; y b) la escuela de la gobernanza orientada a estudiar los cambios en las estructuras administrativas del estado.

${ }^{5}$ En este artículo sólo se analizará el vínculo entre el Estado y la sociedad civil de la triple relación estado-mercado-sociedad. Se reconoce el peso del mercado en el desarrollo de la política, por la extensión de este artículo se definió se decidió realizar un análisis focalizado. El análisis del rol de mercado en el proceso será objeto de otro artículo.

${ }^{6}$ Se trató de la última dictadura cívico-militar, autodenominada Proceso de Reorganización Nacional, ygobernó la Argentina desde el golpe de Estado del 24 de marzo de 1976, derrocando a un gobierno constitucional, hasta el 10 de diciembre de 1983, día que la Argentina recuperó su democracia mediante sufragio con la presidencia de Raúl Alfonsín.

${ }^{7}$ En el 2015 Mauricio Macri asume la presidencia de la Nación (período de cuatro años)y Horacio Rodríguez Larreta la intendencia de la Ciudad (reelecto nuevamente en 2019), ambos por el partido Cambiemos. 
${ }^{8}$ El Proyecto Paseo del Bajo es una de las obras más ambiciosas del GCBA para incorporar el sur al norte. Trata de un corredor vial de 7 kilómetros de extensión que conecta las autopistas Buenos Aires-La Plata e lllía para evitar el ingreso a la ciudad del tránsito pesado. Las obras terminaron en 2019 y cuenta con un carril subterráneo (pesado) exclusivo de camiones y al nivel de la superficie con cuatro carriles por lado para autos, llamado Par Vial permitiendo mayor fluidez a la conexión entre Puerto Madero y la Costanera.

${ }^{9}$ En la zona conocida como Catalinas Norte II se llevará adelante el emprendimiento Catalinas Río donde ya se anuncia que será el edificio más grande del país. Con una extensión 240 metros de largo estará comprendido por dos torres entrelazadas con vistas exclusivas al Río de la Plata, ubicándose en frente a Dársena Norte donde se terminó el Paseo del Bajo.

${ }^{10}$ El Distrito Quartier Puerto Retiro es un emprendimiento privado, aún en obra, basado en la edificación de 3 complejos edilicios con usos diferenciales (oficinas corporativas, la refuncionalización del emblemático Hospital Ferroviario como edificio de Lofts residenciales aptos profesional y el edificio de Studios, residenciales, alquiler temporario y apto profesional) conectados por un paseo gastronómico-comercial. En la página web del emprendimiento se señala en primera plana su ubicación excepcional al encontrarse sobre el nuevo Paseo del Bajo y conformando la proa de Puerto Madero, con directa conexión a la Autopista Illia, la Costanera Norte, la Estación Retiro y la Plaza San Martín. (Disponible en internet: http://www.distritoquartierpuertoretiro.com.ar/, visto 06/03/2020).

${ }^{11}$ El Gobierno de la Ciudad de Buenos Aires proyecta poner en valor zonas relegadas del área que conecta Retiro con Puerto Madero y Costa Salguero e incluso en las zonas de borde de las villas con la ciudad consolidada. Para ello promueve obras como el Paseo de los Inmigrantes, que será una continuidad verde del eje Plaza San Martín, la jerarquización del acceso de turistas desde la Terminal de Cruceros, la restauración de la terminal de trenes Mitre, el reordenamiento de las paradas de colectivo e incluso la relocalización de la espera de camiones con una plataforma ideada cerca de la zona de Costa Salguero. También en los límites se trasladarán la sede del Ministerio de Educación de la Ciudad, oficinas del Banco Interamericano de Desarrollo (BID), Banco de la Ciudad y AFIP (rentas nacionales).

${ }^{12}$ Vale señalar que gran parte de la política habitacional local (e incluso argentina) se implementa con casi nulas instancias de toma de decisión para sus destinatarios. Para profundizar en este aspecto, se sugiere retomar las reflexiones de Zapata (2017).

\section{Bibliografía citada}

AGUILAR VILLANUEVA, Luis. Gobernanza y gestión pública. Ciudad de México: Fondo de Cultura Económica, 2006.

AL-LAS. Un lugar en la mesa global. Los gobiernos locales como tomadores de decisiones en la 
agenda mundial. Ciudad de México: Gobierno de la Ciudad de México, 2017.

ANDREANUCCI Luciano, NEUFELD María Rosay RAGGIO, Liliana. Elementos para un análisis de programas sociales desde la perspectiva de los receptores. Los Polvorines: Instituto del Conurbano - UNGS, 2000.

BANCO MUNDIAL. Reforming public institutions and strengthening governance. Una estrategia del Banco Mundial. Resumen ejecutivo. Washington DC, 2000.

BORJA, Jordi, y CASTELLS, Manuel. Local y Global. La gestión de las ciudades en la era de la información (2000). México: Santillana, 1997.

BRENNER, Neil. Urban governance and the production of new state spaces in Western Europe 1960-2000. Review or International Political Economy, 11(3), 447-488. 2004. https://doi.org/10.1007/978-1-4020-9480-4 3.

BRENNER, Neil, y THEODORE, Nik. Espacios del neoliberalismo: la reestructuración urbana en América del Norte y Europa Occidental. Londres: Blackwell Publishers, 2002.

CAPALBO, Tomás. La participación en disputa: significados en pugna en el marco del proceso de urbanización de la Villa 31. XIII Jornadas de Sociología. Facultad de Ciencias Sociales, Buenos Aires: UBA, 2019a.

CAPALBO, Tomás. La disputa por la participación y la noción de participación en disputa: una reflexión desde el proceso de urbanización de la Villa 31 (2015-2019). Encuentro de la Red de Asentamientos Populares: aportes teórico -metodológicos para la reflexión sobre políticas públicas de acceso al hábitat. 23 y 24 de mayo de 2019. Facultad de Arquitectura, Urbanismo y Diseño. Córdoba: UNC, 2019b.

CARDENALLI, Graciela y ROSENFELD, Mónica. La gestión asociada: la utopía realista. 1er Congreso Nacional de Políticas Sociales. Buenos Aires: UNQ, 2002.

CATENAZZI, Andrea, y CHIARA, Magdalena. La participación en la gestión: alcances y límites en su institucionalización. En M. Chiara, y M. M. Di Virgilio, Gestión de la política social (págs. 201-214). Buenos Aires: Ed. Prometeo Libros, 2009.CEPAL. Plan de Acción Regional para la implementación de la Nueva Agenda Urbana en América Latina y el Caribe (2016-2036). Santiago de Chile: CEPAL, 2016.

COHEN, Jean y ARATO, Andrew. Sociedad civil y teoría política. México: Fondo de Cultura Económica, 2000.

CORAGGIO, José Luis. Las políticas públicas participativas: ¿Obstáculo o requisito para el desarrollo local? II Seminario Nacional "Fortaleciendo la relación Estado-Sociedad Civil para el Desarrollo local". Buenos Aires: CENOC-CEDES-UNGS, 2003.

CUENYA, Beatriz. Grandes proyectos y sus impactos en la centralidad urbana. Carajillo de la ciudad, Revista Digital del Programa Gestión de la Ciudad(3), 2011.

CUNILL GRAU, Nuria. La rearticulación de las relaciones Estado-Sociedad: en búsqueda de nuevos sentidos. Revista CLAD Reforma y Democracia(4), 1995. 
DE LA MORA, Luis. Porvenir local. Participación popular en la conquista de ciudadanía. Evaluación de procesos de participación en el Plan de Recuperación de barrios marginales de Recife (Brasil). Tesis Doctoral. París: Universite de Paris I, 1992.

DE LA MORA, Luis. Aferição da qualidade da participação dos agentes envolvidos em mecanismos de gestão democrática do desenvolvimento local. Uma proposta metodológica. Recife: Universidade Federal de Pernambuco, 2002.

DE MATTOS, Carlos. Globalización, negocios inmobiliarios y mercantilización del desarrollo urbano. En Córdova Montúfar Marco (coord), En lo urbano en su complejidad: una lectura desde América Latina. (Vol. Colección, pp. 35-62). Quito: Flacso, 2008. https://doi.org/10.4067/S0250$\underline{71612009000100007}$

DE MATTOS, Carlos. Globalización y metamorfosis metropolitana en América Latina. De la ciudad a los urbano generalizado. Revista de Geografía Norte Grande(47), 81-104, 2010.

DÍAZ ORUETA, Fernando. Sociedad, espacio y crisis en la ciudad neoliberal. En J. Cucó (ed.), Metamorfosis urbanas. Ciudades españolas en la dinámica global (pp. 81-107). Barcelona: Icaria, 2013.

GARCÍA DELGADO, Daniel y DE PIERO, Sergio. Articulación y relación Estado - organizaciones de la sociedad civil. Modelos y prácticas en la Argentina de las reformas de segunda generación. Buenos Aires: FLACSO, 2001.

HARVEY, David. El "nuevo" imperialismo: acumulación por desposesión. Socialist Register, 40, 6389, 2004.

HARVEY, David. Breve historia del Neoliberalismo. Madrid: Editorial Akal, 2007.

INDEC. Informe técnicos: Índices de precios al consumidor. Vol. 3, n 7 . Buenos Aires, 2019.

JESSOP, Bob. The future of the capitalist state. Cambridge: Polity Press, 2002.

JORDÁN, Ricardo, RIFFO, Luis, y PRADO, Antonio. Desarrollo sostenible, urbanización y desigualdad en América Latina y el Caribe. Santiago de Chile: CEPAL, 2017.

ORGANIZACIÓN DE COOPERACIÓN Y DESARROLLO ECONÓMICO (OCDE). Estándares de Calidad para la Evaluación del Desarrollo. Serie: Directrices y Referencias del CAD. Madrid: Ministerio de Asuntos Exteriores y de Cooperación, 2001.

ORGANIZACIÓN DE LAS NACIONES UNIDAS (ONU). Hábitat III Nueva Agenda Urbana. 2017.

OSZLAK, Oscar. Merecer la ciudad. Los pobres y el derecho al espacio urbano. Buenos Aires: Hvumanitas-Cedes, 1991.

PELLI, Víctor. Habitar, participar y pertenecer. Acceder a la vivienda, incluirse en la sociedad. Buenos Aires: Edit. Noduko, 2007.

RODRÍGUEZ, María Carla. Políticas de hábitat, villas y ciudad: Tendencias actuales y futuros posibles (Buenos Aires, Argentina). Revista Oculum, 15(3), 495-517, 2018. 
RODRíGUEZ, María Carla \& DI VIRGILIO, María Mercedes. Coordenadas para el análisis de las políticas urbanas: un enfoque territorial. En M. C. Rodríguez y M. M. Di Virgilio, Calidoscopio de las políticas territoriales. Un rompecabezas para armar (pág. 402). Buenos Aires: Prometeo Libros, 2011.

RODRÍGUEZ, María Florencia y VITALE, Pablo. Dinámicas urbanas y hábitat popular. Vaivenes de una política fallida de integración social y urbanística en la Comuna 1. En Rodríguez y Di Virgilio (Comp.) Territorio, políticas habitacionales y transformaciones urbanas. Buenos Aires: Espacio, 20016

ROFMAN, Alejandro. Participación de la sociedad civil en políticas públicas: una tipología de mecanismos institucionales participativos. VI Conferencia Regional de ISTR para América Latina y el Caribe. Salvador de Bahía: ISTR y CIAGS/UFBA, 2007.

SEHTMAN Alejandro. La reproducción política de la precariedad urbana: el caso de la Villa $\mathbf{3 1}$ (1996-2007). Tesis de Maestría en Políticas Públicas y Gerenciamiento del Desarrollo. Universidad Nacional de San Martín/Georgetown University, 2009.

SASSEN, Saskia. Localizando ciudades en circuitos globales. Eure, 29(88), 5-27. 2003. https://doi.org/10.4067/S0250-71612003008800001

SASSEN, Saskia. El reposicionamiento de las ciudades y regiones urbanas en una economía global: ampliando las opciones de políticas y gobernanza. Eure, XXXIII(100),

9-34. 2007.

Secretaria de Integración Social y Urbana -SISU-. Informe sobre el empadronamiento 2017. Buenos Aires: Gobierno de la Ciudad Autónoma de Buenos Aires, 2017.

SNITCOFSKY, Valeria. Clase, territorio e historia en las villas de Buenos Aires (1976-1983). Quid 16, 2, 46-62. Buenos Aires, 2012.

THEODORE, Nik, PECK, Jamie, \& BRENNER, Neil. Urbanismo neoliberal: la ciudad y el imperio de los mercados. Revista Temas Sociales(66), 2009.

ZAPATA, María Cecilia. La política habitacional bajo la lupa. De los programas llave en mano a la autogestión del hábitat. Buenos Aires: Editorial Teseo, 2017. https://www.teseopress.com/politicahabitacional.

ZURBRIGGEN, Cristina. Gobernanza: una mirada desde América Latina. Perfiles

Latinoamericanos, 19(38). 2011.

Notas periodísticas:

DIAGONALES.COM. La sociedad entre Larreta y Macri para hacer negocios con el Paseo del Bajo y la Urbanización de la Villa 31. 30 de marzo de 2019 [accesado: 18 de marzo de 2020]. Disponible en: https://bit.ly/3ab8ehT. 
Trabalho enviado em 25 de janeiro de 2019

Aceito em 12 de abril de 2020 